\title{
Driving institutional engagement in WIL: Enhancing graduate employability
}

\author{
Sonia Ferns ${ }^{1}$ (Project Leader Work Integrated Learning), Linda Lilly (Project Manager)
}

\section{S.Ferns@curtin.edu.au; I.lilly@curtin.edu.au}

${ }^{1}$ Curtin University

\begin{abstract}
Authentic learning experiences that replicate workplace settings are essential elements of the student experience for optimising graduate employability outcomes. Work Integrated Learning (WIL) supports the development of generic attributes which are highly regarded by employers through embedding authentic learning experiences in curricular and co-curricular programs. The regulatory and standards-based environment which monitors and controls higher education institutions' operations is increasingly focussing on WIL and the employability capabilities of graduates. In addition, external stakeholders such as employers and community agencies expect that graduates are prepared for a global and uncertain job market. The ultimate aim is to build a competitive and sustainable Australian economy through ensuring a highly-skilled population. Higher education is considered a key mechanism for achieving this ambition. Reconceptualising curriculum development and assessment strategies is required in order to address these societal demands.

Embedding the development of employability capabilities in curriculum to ensure work-ready graduates is a priority for Curtin University as it aspires to provide authentic learning experiences where students apply theoretical concepts in real-world settings. Scaffolding skill development across curriculum is fundamental to quality curriculum design. Flexible industry and community partnerships are integral to implementing a practice-based curriculum, enabling the development of professional practice to be an integral component of the degree program. This paper presents a three-year Strategic Project, which aimed to enrich the student experience through establishing an institutional framework for WIL, as a case study to inform further WIL initiatives. It outlines strategies implemented to achieve the strategic goals, to introduce innovative approaches for establishing an institutional framework, and to enhance the student experience through WIL.
\end{abstract}

Keywords: work integrated learning, graduate employability, authentic learning, partnerships

\section{Introduction}

Higher education institutions are facing a profoundly challenging landscape, arguably the most significant in the history of universities (Thomas, 2012; Varghese, 2011; Ernst \& Young, 2012). Factors such as: the widening participation agenda; a vigorous competitive market; the demand for enhanced employability outcomes for students; rigorous quality accountability measures; the recognition of the value of industry and community partnerships; and the impact 
of rapidly changing technologies influence how business is conducted. These influences require universities to reconceptualise teaching and learning approaches and rethink leadership strategies and institutional priorities (Barber, Donnelly, \& Rizvi, 2013). Despite the notion of universities as creators of knowledge and innovation, they are recognised as highly reluctant to reform (Fullen \& Scott, 2009). The history and long-standing traditional practices of academia, while respected and recognised as central to growth and development, can be barriers to transformation and adaptation in response to society's changing needs.

\section{Context}

\section{Changing workforce requirements}

Global trends such as communication, digital technologies, and social, political and economic influences are transforming the workplace. Automation of traditionally manually operated machinery is redefining the workforce. People will not only have multiple jobs but career direction and focus will shift as technological changes and emerging professions impact on the landscape (Hagel, Brown, Mathew, Wooll, \& Tsu, 2014). Continuous lifelong learning will be imperative to being able to cope with the ever-changing job market. The challenges confronting society in the coming decades will require a skilled, innovative workforce to identify sustainable solutions (EY, 2015). Constant retraining and reskilling will be required to ensure currency and relevance of employability skills that contribute effectively to corporations and the economy. Autonomy, innovation and initiative are increasingly becoming a priority for employers seeking workers who make a difference to an organisation through entrepreneurship and creativity, giving them the competitive edge. Universities have an obligation to ensure students have opportunities to network with industry and gain skills throughout their studies that equip them with the skills necessary for a rewarding and challenging career (Edwards, Perkins, Pearce, \& Hong, 2015).

\section{Role of the university}

Australia values education as a mechanism for building a skilled and productive workforce that contributes effectively to a sustainable and globally competitive economy. Education is perceived to impact on three levels:

- economic and intellectual value for individuals;

- economic and productivity value for society; and

- civic benefits for society whereby education nurtures engaged citizens who contribute to society in positive ways (Hagel et al., 2014).

The role of the university is undergoing a fundamental transformation in terms of its role in society, mode of operation, and economic structure and value (Ernst \& Young, 2012, p. 4). Universities are no longer the creators and keepers of knowledge, with enhanced connectivity meaning rapid access to and transfer of knowledge. With global competition, heightened scrutiny of stakeholders and transparency of information, universities need to be accountable. With reduced budgets, increased costs to students, and decreasing graduate employment, the return on investment of a university education is in question (Barber et al., 2013). The university campus needs to change shape and purpose to become a place of sharing, collaboration and cooperation to discover new ways of doing things.

The content-focussed approach typical of a university education is no longer providing students with proficiencies and the transferrable skill set required for a fruitful career in an unknown, unpredictable future job market (Thomas, 2012). Students need to be exposed to real world learning opportunities where they engage in authentic problem-solving and build intellectual capacity through applying theoretical concepts in practice-based settings. The boundaries between university and community should be blurred to provide a more holistic and inclusive education (Ferns, Campbell, \& Zegwaard, 2014). 
Work Integrated Learning (WIL) is high on the national agenda and gaining attention as a key strategy for universities to address the demands of stakeholders such as industry, community, students and government. With increasing accountability facing the higher education sector and societal demands for the higher education experience to prepare graduates for the dynamic environment of a global workforce, curriculum development and focus requires a paradigm shift (Yorke, 2011). WIL is a contextual-dependent, highly complex and multifaceted pedagogical approach (Hodges, 2011). It encompasses the intentional integration of theory and practice where curriculum is informed through consultative and collaborative engagement with stakeholders external to the institution. Establishing an institutional culture where endeavours to establish sustainable and proactive partnerships with external stakeholders are recognised through workload allocation and reward, requires a shift in focus and reorganisation of business infrastructure.

\section{Authentic student experience}

At the heart of WIL curriculum are authentic and relevant student experiences which ultimately boost the development of employability skills and employment prospects for graduating students. The student experience is enhanced through authentic learning experiences in settings that reflect the workplace (Ferns, Smith, \& Russell, 2014c; Yorke \& Knight, 2004). Authentic learning experiences are designed to reflect real world scenarios (Shavelson, Klein, \& Benjamin, 2009) with students being motivated by tasks that are perceived relevant to the world of work and involve the application of skills such as critical thinking, creativity and innovation. Authentic assessment, similarly incorporates students performing real-world tasks that require meaningful application of theoretical concepts in a practical setting (Mueller, 2012). An authentic student experience is fundamental to incorporating a WIL philosophy across an institution. WIL supports the provision of authentic learning, in a variety of contexts, within curricular and co-curricular programs, thus facilitating the development of generic skills highly sought after by employers (Ferns et al., 2014a).

\section{The National WIL Strategy}

Australia has driven some landmark initiatives focussed on strengthening university and business partnerships to promote innovative WIL approaches thereby enhancing the employability skills acquired by students during their university studies. The Statement of Intent (Universities Australia, 2014a), released in February 2014, was a collaborative initiative between the Australian Collaborative Education Network (ACEN), Chamber of Commerce and Industry (CCI), Business Council of Australian (BCA) and Australian Industry Group (AIG). Commitment to this intent was evidenced by the release of the National WIL Strategy on 11th March 2015, a strategy developed by the same parties in an effort to realise the initiatives implicit in the Statement of Intent (Universities Australia, 2014b). Given the benefits of WIL to employability, workforce skills and productivity, the National WIL Strategy outlines key areas for action that supports educators to work with industry and community based employers, ensuring a sustainable increase and broadening of WIL opportunities to develop our human capital and competitiveness of the economy. The National WIL Strategy highlights the need to develop innovative, problem-solving and entrepreneurial skills through collaboration with external partnerships to afford students the skills required for employability in an unpredictable future (Foundation for Young Australians, 2015).

\section{Driving institutional change}

Embedding innovative practices to execute an ethos that challenges traditional institutional protocols requires a strategic approach with initiatives introduced in a considered and developmental manner. Pivotal to organisational change is the empowering of staff through 
the identification of champions who, through passion and conviction, have a persuasive influence on those reluctant to adopt new methods in operation. Gladwell (2001) refers to these champions as 'messengers'. With a cohort of supporters who support the rationale underpinning the innovations, the likelihood of systemic adoption is increased.

This paper presents a case study of a purposeful approach to the implementation of a threeyear strategic project. The overarching aim of the project was to enhance institutional capacity by establishing and implementing a WIL framework for enhancing the student experience through the provision of curricular and co-curricular opportunities to augment employability capabilities in graduates. A carefully sequenced combination of strategies which focused on staff engagement, consultation with executive management, and the involvement of the student body, formed the basis of the project. Pivotal to driving university-wide commitment and agreement was regular showcasing of best-practice and sharing teaching and learning initiatives that promoted WIL activities. This case study highlights the value and subsequent impact of strategic leadership which was pivotal to driving a cultural shift and facilitating systemic adoption of innovation within the organisation.

\section{Project overview}

The three-year project, which was initiated in early 2013 with the allocation of targeted strategic funding, aimed to enhance the employability of Curtin graduates through industry and community relationships, an experiential curriculum, and co-curricular work experience opportunities. The strategies implemented to achieve the University's strategic goals, introduce innovative approaches for establishing an institutional framework and enhancing the student experience through WIL, are outlined below.

The key objectives of the project were to:

1. Develop a sustainable institutional framework for defining, positioning and evaluating WIL.

2. Provide a quality WIL student experience that aligns graduate capabilities to meet student, graduate and employer expectations.

3. Differentiate Curtin through a systemic and collaborative approach to implementing curricular and co-curricular WIL aligned to industry and community needs.

4. Be recognised as leaders in the sector, by employers and in the community in facilitating engagement and partnership opportunities.

5. Evidence graduate employability capabilities across the student lifecycle.

The project plan was based on using a phased approach. While the various phases were incremental, there was also an overlap of strategies as the preceding initiatives informed future plans. The phases included: 
- Establishing a cohesive WIL Team

2

- Building an institutional framework

3

- Community and industry engagement

4 - Staff engagement

5

- Student engagement

6

- Dissemination and collaboration

7

- Project sustainability

\section{Establishing a cohesive WIL team}

Prior to embarking on the strategic directives of the project, establishing a cohesive and connected team was of critical importance. Through several strategic planning sessions the team explored and identified the required team structure and identified the roles and responsibilities of team members. This process involved the negotiation of a strategic plan that included formulating a vision, mission and strategic goals for the WIL team that aligned to the broader strategic aims of the project and the University. Sharing the emerging purpose and destiny of the group shifts a community from a reactive to a creative orientation (Senge, 1994, p. 298).

\section{Strategic plan of the WIL team}

The WIL Strategic Project was a key strategic initiative of the University and aligned to the Transforming Learning at Curtin program. Within this context a clear team identity was established with an agreed vision statement and mission as outlined below:

Vision:

A leader in Work Integrated Learning actively engaging with students, faculty, industry, business, community and government to provide authentic, interactive and personalised learning experiences for our students, equipping them with professional and employability skills for the future.

\section{Mission:}

1. Engage students through authentic work integrated learning experiences.

2. Facilitate curricular and co-curricular work integrated learning opportunities for students to enhance graduate employability.

3. Develop and sustain mutually beneficial relationships with communities both internal and external to Curtin.

4. Embed WIL in curriculum.

5. Provide support to staff to embed WIL into curriculum

With an agreed way forward, the WIL team were poised to determine the shape of the team and reframe position descriptions to ensure individual roles and responsibilities were framed to explicitly address the team vision and mission and ultimately the project's key objectives (Ferns et al., 2014b, p.2). While a time-consuming and tenuous task, this aspect of the project 
implementation provided the foundation for future tasks. To complete the team identity and establish a brand that would be recognised across the institution, a symbol was developed that reflected the WIL philosophy.

\section{Building an Institutional Framework}

This phase of the project incorporated several key tasks paramount to the university community embracing the WIL philosophy.

\section{WIL Guidelines}

The intention of the WIL Guidelines (Curtin University, 2014a) was to determine an agreed definition for WIL and to establish a university-wide framework for developing partnerships with industry and community which would inform curriculum and engage students in relevant, skill-based experiences evidenced by realistic assessment profiles. The guidelines were not intended to be a prescriptive policy compliance document. By contrast, the purpose was to establish an agreed philosophical approach to WIL which enabled flexibility and diversity for different discipline contexts. The WIL Guidelines incorporate quality indicators against several domains. The domains include learning design, assessment and moderation of WIL, delivery of WIL programs, community engagement and industry partnerships, and innovation in WIL. Extensive consultation was undertaken across all levels of the university prior to endorsement. While the Guidelines provided a basis for building the institutional capacity, the process of agreeing on the final version facilitated robust discussion at both executive leadership and practitioner level across the university ensuring WIL was firmly on the university agenda.

\section{Governance}

It was imperative that initiatives and best-practices emanating from the WIL Strategic Project had the support of groups and individuals with the capacity to influence executive-level decision-making. Therefore, a WIL Steering Committee and WIL Advisory Group was set-up to establish a consultative approach to implementing WIL programs and ensure efficient communication. Members of these strategic groups included faculty representatives and managers who have substantial input in decision-making at the university. Members provided advice on project processes, initiatives and directions which informed progress, implementation and future sustainability.

In addition, a Governance Group involving representatives from Legal and Compliance, Health and Safety, and Risk Management was established to ensure that policy and logistical processes for WIL were streamlined and efficient. Consistency of documentation and expectations and easy access to information was essential in the management of innovation and change. Templates and processes for negotiating legal agreements, adhering to health and safety regulations, and following appropriate risk assessment practices were developed and disseminated across the University. Cohesive and connected policy documents were essential for successful, systemic implementation of WIL (McNamara, 2011). Relevant manuals and policies were revisited, updated and approved to reflect decisions of the Governance Group.

The work flow and resources designed to facilitate consistent governance of Fieldwork, one form of WIL, are shown in the Fieldwork Flowchart in Figure 1 below. 


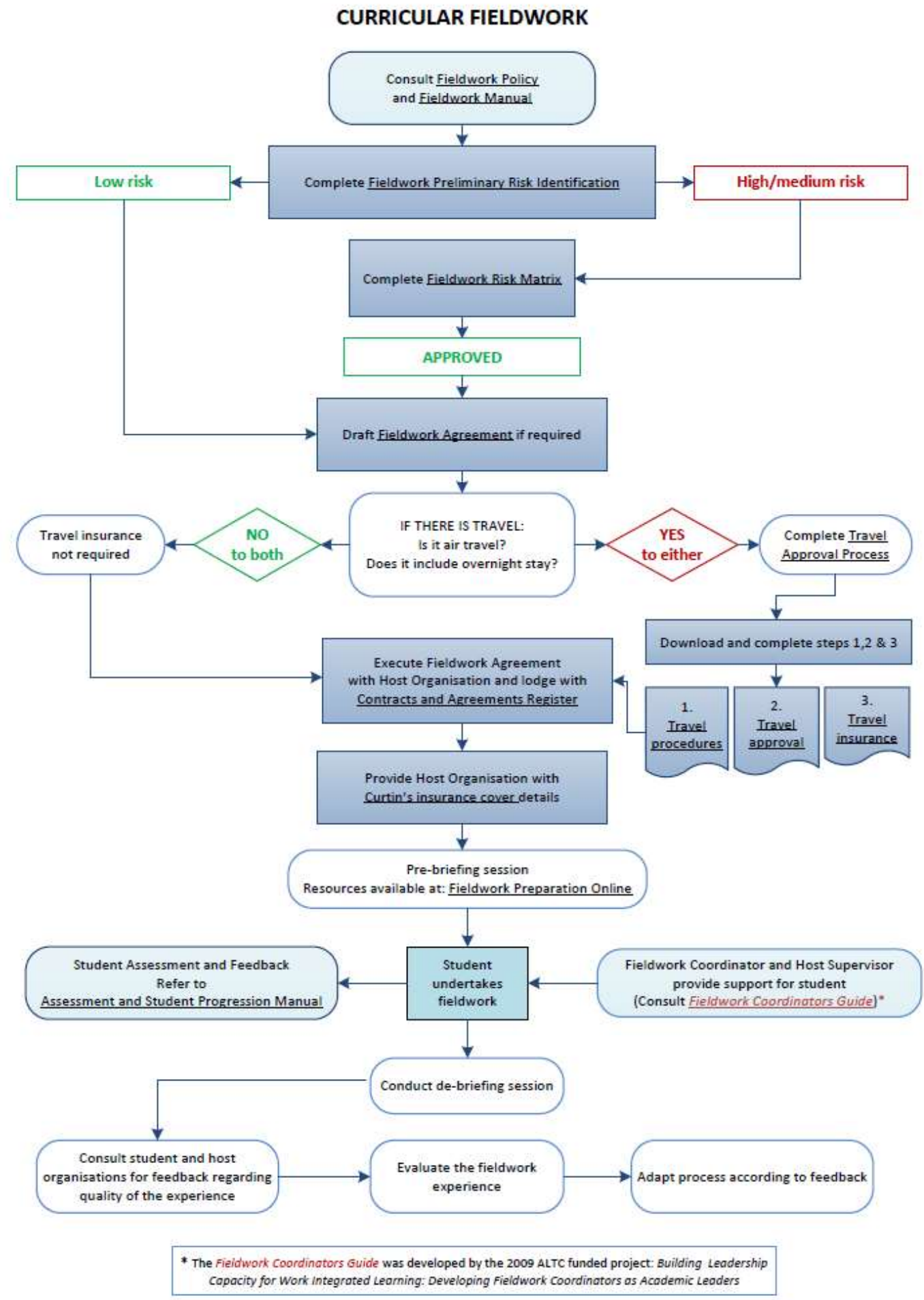

Figure 1. Fieldwork Flowchart summarising Governance Processes and Tasks

\section{Communication strategies}

Communication provides the nexus between drivers of change and the community required to embrace that change. Calculated and deliberate communication channels are pivotal to the dissemination of innovative practices (George, Collins, Gill, \& Cole, 1987). Champions 
ensconced in faculties are valuable resources for spreading the word. To guarantee that the WIL messages were disseminated throughout the university community, an inclusive communication plan was developed (Ferns et al., 2014b). The plan, created in the early stages of the project, streamlined the process for broadcasting messages and showcasing bestpractice to staff and students across the institution. It comprised four distinct sections: meetings, written and electronic communication, social media and national dissemination. Stakeholder meetings included regular face-to-face encounters with all levels of the university where information was shared and feedback sought. These meetings with formal agendas and minutes provided a conduit to all university personnel (Ferns et al., 2014b. p. 58). Written and electronic communication included the regular reporting requirements which, while a time intensive activity, were perceived as valuable mechanisms for dissemination, provision of updates on progress and addressing accountability requirements.

Several key communication initiatives proved pivotal to spreading the word and promoting WIL activities across the university. A monthly electronic newsletter titled the GoodWIL Newsletter was distributed to both internal and external stakeholders. The newsletter proved to be a popular publication for faculty staff to showcase innovative WIL activities. The WIL website was an important feature of the project as it provided easy access to information about WIL and relevant resources for staff and students. The website was developed over a period of time that allowed for a consultative and collaborative approach with all stakeholders. Both the newsletter and website were useful for highlighting exemplary practice, sharing opportunities and communicating the progress and impacts driven by the WIL project team.

Additionally, an integrated social media strategy was implemented to engage stakeholders in the WIL website and resources, events and professional development opportunities. This included the creation and management of a WIL at Curtin Facebook page; Linkedln group and Blog. The WIL Facebook page, with a total 651 followers, generates regular 'Likes' through organic shares and in response to campaign activities. WIL opportunities were promoted on Facebook and students were able to ask questions and receive accurate and timely responses in real time. The WIL Linkedln group was activated in the latter part of 2015 with the intention of connecting industry and employers with students and the WIL Project team, to share information and resources and to promote discussion of WIL in an open forum. The WIL at Curtin Blog targets students seeking advice and support regarding WIL experiences in an informal format. Implementing a social media strategy has been significant to increasing stakeholder engagement in WIL resources and website and has enhanced the online presence and accessibility of the WIL Strategic Project at Curtin.

In addition, the WIL team attended all university events including Orientation Week, Festival of Learning, Education Abroad Fair, and Careers' Fair to promote WIL initiatives and engage directly with students and staff. The communication strategies employed by the WIL team were carefully considered strategies for facilitating a cultural shift and building institutional capacity through the implementation of a comprehensive communication plan.

\section{Engagement with host organisations}

Integral to establishing successful approaches to WIL are firstly engagement with external organisations, and secondly the considered manner in which this engagement occurs including the brokering, monitoring and maintenance of partnerships to ensure their sustainability. Partnerships with external organisations are complex and occur in many forms. WIL requires strong partnerships between all stakeholders: students, university staff and host organisations. Mutually beneficial and reciprocal WIL activities meet the needs of industry, business, government, community, students, and universities, in developing and delivering authentic learning experiences that benefit all partners/stakeholders (Kay, Winchester-Seeto, Rowe, \& Le Clus, 2014). Communication pathways and information for host organisations need to ensure a clearly articulated connection. Similarly a collaborative and coordinated relationship with host organisations was essential to guarantee optimal input from employers

Ferns, S. \& Lilly, L. (2015). Driving institutional engagement in WIL: Enhancing graduate employability. Journal of Teaching and Learning for Graduate Employability, 6(1), 116-133. 
to enhance the students' learning experiences, to facilitate the development of employability capabilities, and to broaden industry networks (van Rooijen, 2011).

For engagement to be effective, WIL at Curtin University aimed to be:

- Mutually beneficial for all parties-the university, the host organisation/partner and the student must all benefit from the relationship.

- Clearly understood-the University needs to be clear on the unique contribution and value added by their involvement in broader communities.

- Well managed, resourced and supported by the university.

- Meaningful and relevant to academic outcomes.

- Rigorously evaluated and measured.

As a result of adopting these principles for effective engagement, staff at Curtin University were able to:

- Enrich the teaching, learning and research experience.

- Enhance the work-readiness of Curtin graduates.

- Build effective business, industry, government and community relationships that support the teaching and learning experience and leads to excellence in research innovation and sustainability.

- Foster close and ongoing relationships with Alumni and other graduate networks.

- Create and leverage connections to enable the exchange of knowledge and learning.

- Become the preferred provider of work ready graduates in our local communities.

\section{Staff engagement}

Engaging all university staff including WIL practitioners, professional and academic staff, Course Coordinators, Heads of School, and Executive Management was essential for embedding WIL practices in the student experience. Being mindful that staff engagement was central to prompting a cultural shift across the organisation that embraced WIL pedagogy and practices, the project team adopted several key strategies designed to ensure buy-in from all staff.

\section{Staff resources}

A chapter on WIL was written for inclusion in the Teaching and Learning Handbook, the key Curtin University resource for teaching staff (Curtin University, 2014b). The chapter is a concise account with a definition, a link to the WIL Guidelines, a brief explanation of curricular and co-curricular WIL experiences, a description of authentic assessment and a section on developing partnerships to inform curriculum. A print version and electronic version are available for staff. More importantly, the Teaching and Learning Handbook links WIL to the broader teaching and learning context at Curtin (Ferns et al., 2014b).

The academic staff in the WIL team developed an interactive module for the Foundations of Learning and Teaching (FOLT) programme at the University. FOLT is Curtin's primary professional development for teaching staff - including casual employees - thereby reaching a wide audience. The WIL module was designed intentionally to encourage discussion and collaboration about approaches to embedding WIL in curriculum. Attendees were invited to explore WIL approaches relevant to their discipline and were provided with resources to guide the enactment of WIL in the curriculum. 


\section{Authentic Assessment Framework}

Effective, efficient and equitable assessment is a key issue in the implementation of WIL experiences into the curriculum. While there is general agreement across the higher education sector that WIL activities are a valuable component of a degree course, measuring student performance against clear and concise criteria remains a challenge. WIL may take many forms and involves a range of stakeholders such as employers and community groups. Furthermore, WIL may be a class-based activity or occur in the workplace. It is this diversity and complexity of WIL tasks that presents difficulties in designing fair and equitable assessments (Ferns \& Moore, 2012; Smith, Ferns, \& Russell, 2014). Outcomes of WIL experiences may also be dependent on engagement in extra-curricular activities and personal backgrounds, both of which vary greatly across the student population.

In response to these challenges, tools for engaging staff in reconceptualising curriculum have been prepared. The Authentic Assessment Framework (AAF) was developed over an extended period and adapted according to feedback. The AAF is informed by contemporary research and has been trialled with several teaching teams. The purpose of the AAF is to determine the authenticity of assessments and learning activities thus ensuring curricula are developmental and student-focused. The AAF enables curricula to be interrogated by providing the graphic evidence of the level of authenticity in the student experience to ensure real-world relevance (Bosco \& Ferns, 2014). The most valuable aspect of the AAF is the evidence-based approach to curriculum renewal enabling staff to conceptualise the benefits.

\section{WIL descriptors}

Five descriptors were developed to allow unit level recording and course level reporting of WIL in Curtin's data management system. The WIL Attributes are shown in Table 1 below. A sample WIL Chart, showing the spread of WIL Attributes across a course, is shown in Figure 2. The WIL Chart provides evidence of existing WIL in curriculum and highlights opportunities to improve skill development and work readiness of students. The WIL Chart is a useful tool for prompting discussion during course review and renewal.

Table 1: WIL Descriptors in Student One (S1) for Improved Reporting of WIL

\begin{tabular}{|l|l|}
\hline Code in S1 & \multicolumn{1}{c|}{ WIL Attributes } \\
\hline WIL-NA & Not applicable; this unit is not intended to have a WIL experience \\
WIL-NE & Not evident \\
WIL-E & Emerging, WIL evident in some outcomes and assessments \\
WIL-D & Developing, WIL evident in all outcomes and assessments \\
WIL-HD & Highly developed, work or community based experience \\
\hline
\end{tabular}




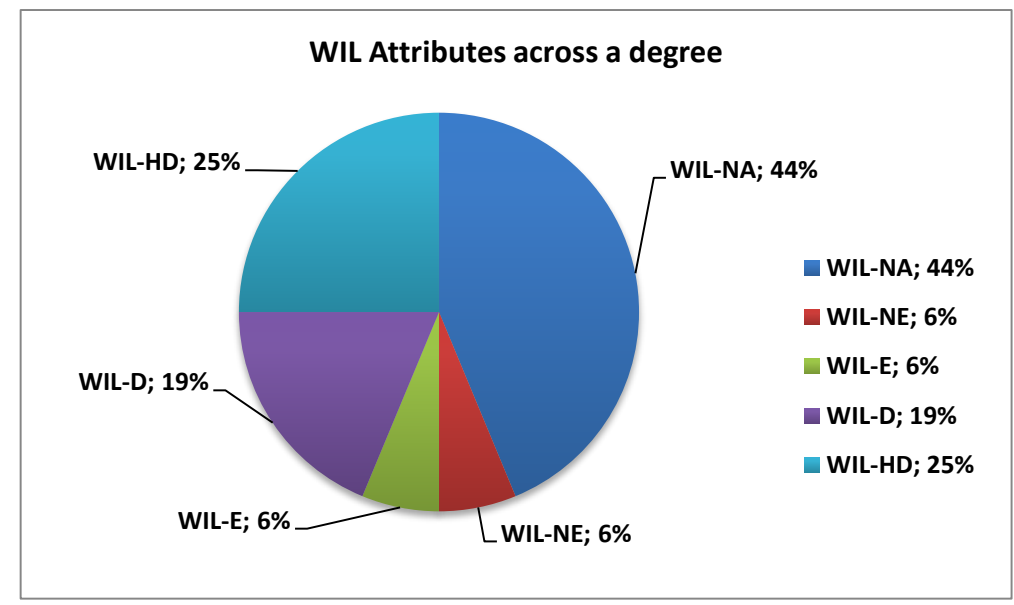

Figure 2: WIL Chart showing WIL Attributes across a Course

\section{Capacity building}

In an effort to disseminate exemplary practices, share university-wide activities, and involve staff in the WIL agenda, the WIL project team conducted events and professional learning opportunities for both academic and professional staff. These events were jointly funded by, and held in partnership with, the Australian Government Office for Learning and Teaching (OLT) project teams and the Australian Collaborative Education network (ACEN). To date these have included:

1. International webinars titled:

- Engaging diverse students in WIL, Financial hardship and international students and WIL;

- Responding to diverse students in WIL;

- Building institutional capacity for student diversity;

- Inclusive WIL: Implications for stakeholders;

- Global mobility in health disciplines: Best practice approaches for international fieldwork placements;

2. A workshop titled Assessing Work Integrated Learning;

3. A community of practice event called Let's talk about WIL where WIL practitioners were invited to showcase best-practice WIL initiatives;

4. Poster presentations;

5. A variety of sessions at the annual Curtin University event: Festival of Learning;

6. Several presentations in both 2014 and 2015 at the WA Teaching and Learning Forum which is an annual inter-university conference in WA;

7. Conference presentations and refereed papers.

These events attracted staff from a number of universities including, in the case of the webinars, colleagues from over thirty Australian and several international tertiary institutions.

The WIL team has also been involved in the development and delivery of Global Perspectives in Work-Integrated Learning, an online professional development program for WIL practitioners. Leaders in WIL from Australia, Canada, New Zealand and Sweden, through their respective national WIL associations (ACEN, CAFCE, NZACE and VILAR) worked collaboratively to design the module which has attracted high demand internationally. The inaugural delivery took place from April to July 2015 with 35 participants. The second offering of the program began in October 2015 and concluded in December 2015. 


\section{Staff recognition}

Recognising and rewarding staff engagement with WIL was critical to the perception by staff of the value-added of participation (DeZure, 2000). A number of initiatives were designed to encourage staff participation. The first was the provision of funding for ten small-scale facultybased WIL in Curriculum Projects, with each faculty allocated funding for two projects. It was anticipated that the initiatives which emerged from the grants would be embedded into curricula in 2015. Staff across the University competed for the funding and those who were successful were required to submit a final report highlighting the outcomes of their projects and were invited to present a poster at the 2015 Festival of Learning. As a consequence of this initiative a proposal has been made to include an award for innovative approaches to teaching and learning that incorporate a WIL pedagogy in the university wide Excellence in Teaching awards.

Staff participation in WIL activities was also encouraged by the involvement of the WIL Team in collaborations and research activities which highlighted to staff the credibility and integrity (Fullen \& Scott, 2009) of not only the WIL projects, but also the team and its achievements on both the national and international stage. This was a powerful influence on staff willingness to engage (Ferns et al., 2014b). In particular, the final OLT Report Assessing the impact of WIL on student work-readiness (published in October 2015) substantiates the impact of WIL on graduate employability and has been a catalyst for driving the university-industry partnership agenda. Participation of the WIL team on several OLT project teams including: Building institutional capacity to enhance access, participation and progression in Work Integrated Learning (WIL), Quality in Australian outbound student mobility programs: Establishing good practice guidelines for International Work-Integrated-Learning in Health Sciences, Improving work placements for international students, their mentors and stakeholders, and Developing strategies to maximise industry contribution and engagement with the WIL experience has also raised the profile of WIL and encouraged staff engagement.

\section{Student engagement}

Several strategies were developed for the explicit purpose of engaging the student cohort in the WIL project. Students attended preparation workshops prior to going on a WIL workplacement. To ensure students gained maximum benefits from a work-based experience, carefully designed pre briefing and de-briefing sessions were held. Students were also provided with ongoing support while on placement to ensure any emerging issues were dealt with and learning outcomes were optimised. In addition, the WIL team created a WIL Blackboard site as a way of communicating with students to provide regular updates and as a mechanism to register for WIL activities.

The online Fieldwork Preparation module proved to be a useful student resource with the WIL team updating content and revitalising the module in an effort to engage more students. The WIL team also offered a series of interactive workshops where students engaged in conversations about the culture of the Australian workforce, work-readiness skills, selfreflective practice, and ethical behaviour. Some workshops were specifically designed to cater to international students in an effort to provide targeted support that enabled them opportunities to become familiar with Australian business and industry.

Two WIL units (subjects) were developed by the WIL team and approved: WORK3001 Engaging with Community and WORK3000 Engaging with Industry. These units were designed to provide students with a WIL experience that nurtured employability capabilities which were evidenced by authentic assessment. Students who had the capacity within course structures, enrolled in the units and gained recognition as a part of their studies. The unit WORK3000 Engaging with Industry was delivered in the Summer School 2015 study period with 46 international students enrolling. The students were afforded the opportunity to experience the culture of the Australian workforce thereby enhancing their global mobility. 
Students enrolled in the WIL Units also had the option to undertake their placements internationally.

The WIL team used various communications channels, including faculty contacts, a WIL at Curtin Facebook page to promote community and industry-based opportunities, events and WIL activities to the student body. The team also engaged with students directly on campus through events such as the Careers Festival and Orientation Week. The Australian Collaborative Education Network (ACEN) scholarship was administered annually by the WIL team on behalf of ACEN. Student representation was also included on the governance groups convened by the WIL project team such as the WIL Advisory Committee.

Global mobility opportunities for students were provided by New Colombo Plan Mobility Grants, a Government funded initiative which provides opportunities for Australian undergraduate students to participate in international work-based experiences. The WIL team was successful in winning New Colombo Plan Mobility Grants which provided funds for students to undertake short-term internships in China and Cambodia with host organisations offering placements for Chemical Engineering, Food Science and Technology, and Education students. Existing governance processes for international placements were implemented and refined, including development of new resources, liaising with third-party providers to ensure that the student experience met required standards and translation of relevant legal agreements into Mandarin. Culture Shock presentations were delivered to prepare students travelling overseas.

Collaboration with the Scholarships and Admissions Office provided another avenue for enhancing engagement between the WIL Team and students, and promoting further overseas internship opportunities.

\section{Collaboration and dissemination}

Internal and external networks were essential for the WIL team to optimise the impact of the project deliverables and facilitate extensive communication channels. Figure 3 , below, provides a visual representation of the internal collaborations that were integral to successful WIL innovations at the University. These collaborations ensured the WIL initiatives were connected to the organisational infrastructure and embraced holistically.

Multiple external collaborators are essential to institutional capacity building. Many of these are outlined in the section above on community and industry engagement. In addition to these partnerships, the WIL team established strong networks with peak educational bodies focused on WIL and engagement. The WIL team was represented on the Board of Directors for both ACEN and Engagement Australia, as well as The National WIL Strategy Reference Group. These collaborations assisted in maintaining up to date information with contemporary WIL developments both internationally and nationally. Furthermore, these connections established collaborative research networks in which the WIL team is involved. As a result, the academic staff in the WIL team are working on several state-based and national research activities with WIL leaders. Several scholarly articles on WIL have been published in academic journals and conference proceedings. 


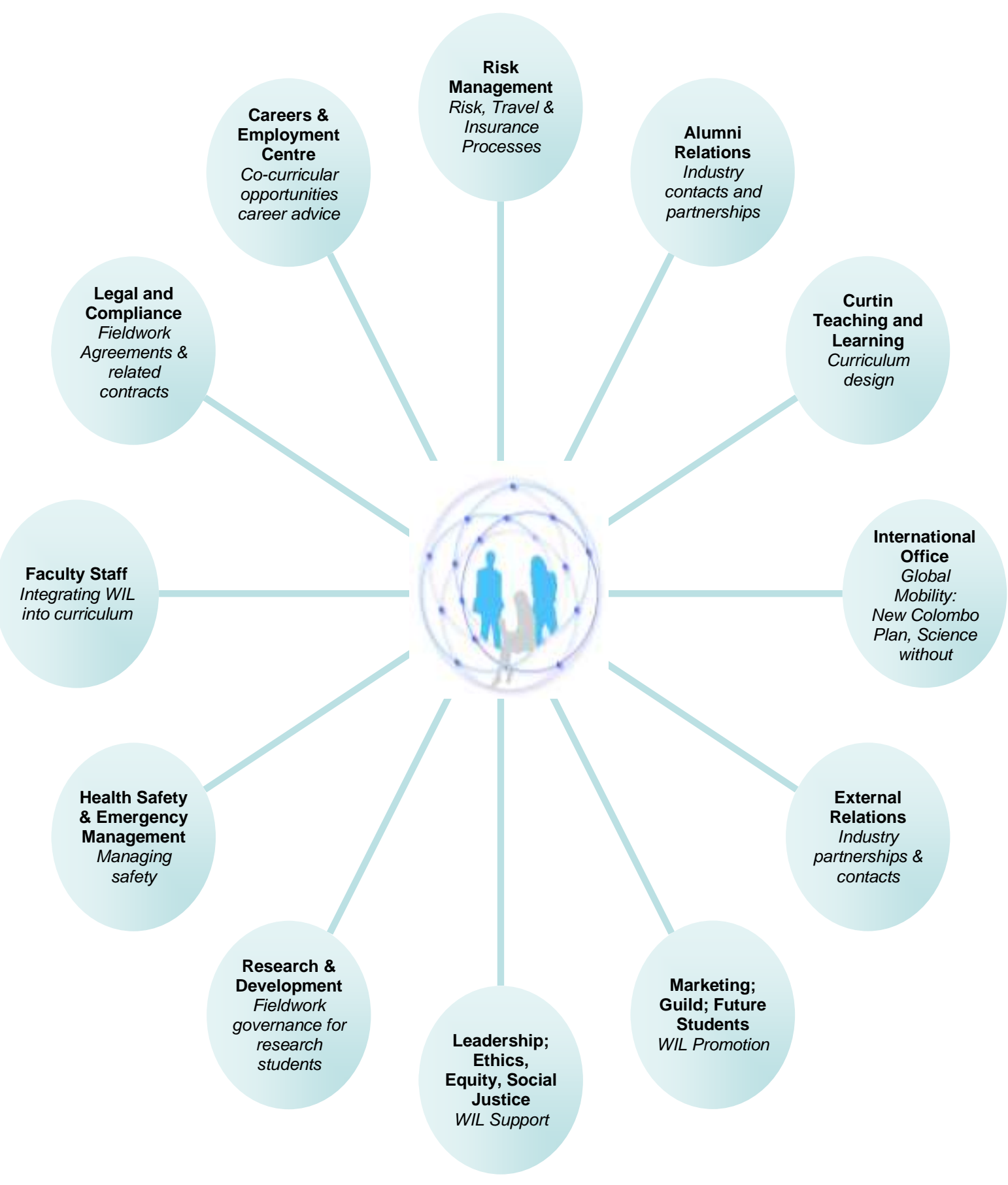

Figure 3: Internal Connections of the WIL Team and their Impact

\section{Sustainability}

Sustainability of the project outcomes and building institutional capacity for the long term requires a multi-pronged approach. The carefully sequenced and executed strategies outlined in this paper underpin the intention to instil sustainable practices across the institution. A targeted initiative was for a representative from the WIL team to reside in each of the faculties. These staff, known as partnership coordinators, had a key role to build both internal and external networks and worked in their faculty to achieve the goals of the project by:

- Building networks/relationships with staff and students; 
- Ensuring an accessible resource and support for staff;

- Facilitating systemic uptake of a WIL institutional framework;

- Streamlining communication channels.

This achieved several key advantages including networking with staff, students and faculty leaders; providing assistance and support pertinent to the particular faculty's needs; directly influencing faculty management groups and individuals; and building a tangible presence that promoted WIL. The aim was for the partnership coordinators to continue post-project with the hope of providing ongoing support of and impetus for WIL activities. The partnership coordinator's role is presented diagrammatically in Table 2 below. Implementing strategies that sustain the WIL project deliverables was the emphasis as the project team embarked on the final stages of implementation with completion scheduled for December 2015.

\section{Table 2: Engagement Roles of the Partnership Coordinators}

\begin{tabular}{|c|c|c|}
\hline SUPPORT FOR STUDENTS & SUPPORT FOR STAFF & SUPPORT FOR PARTNERS \\
\hline $\begin{array}{l}\text { Engage with and register students } \\
\text { for WIL opportunities }\end{array}$ & $\begin{array}{l}\text { Engage with staff through targeted } \\
\text { individual support or attending } \\
\text { teaching and learning meetings }\end{array}$ & $\begin{array}{l}\text { Engage with partners to develop } \\
\text { mutually beneficial, sustainable } \\
\text { partnerships }\end{array}$ \\
\hline $\begin{array}{l}\text { Promote current WIL opportunities } \\
\text { using a variety of modes }\end{array}$ & $\begin{array}{l}\text { Communicate institutional WIL } \\
\text { framework, governance, reporting } \\
\text { requirements }{ }^{*} \text { and resources to } \\
\text { staff ( }{ }^{*} \text { Fieldwork tuition patterns } \\
\text { and WIL Attributes) }\end{array}$ & $\begin{array}{l}\text { Assist partners in selection process } \\
\text { of students for placements }\end{array}$ \\
\hline $\begin{array}{l}\text { Coordinate student responses for } \\
\text { WIL opportunities }\end{array}$ & $\begin{array}{l}\text { Develop and disseminate } \\
\text { resources such as WIL website, } \\
\text { Fieldwork Manual, Authentic } \\
\text { Assessment Framework }\end{array}$ & $\begin{array}{l}\text { Develop and use Engagement } \\
\text { Framework that outlines best } \\
\text { practice }\end{array}$ \\
\hline $\begin{array}{l}\text { Liaise with host organisations to } \\
\text { source placements }\end{array}$ & $\begin{array}{l}\text { Disseminate resources for } \\
\text { governance - policy, forms, WIL } \\
\text { Guidelines }\end{array}$ & $\begin{array}{l}\text { Develop partners' page on WIL and } \\
\text { Fieldwork websites }\end{array}$ \\
\hline $\begin{array}{l}\text { Conduct pre-briefings to prepare } \\
\text { students for placement }\end{array}$ & $\begin{array}{l}\text { Encourage and promote } \\
\text { engagement in professional } \\
\text { development opportunities }\end{array}$ & $\begin{array}{l}\text { Develop resources such as } \\
\text { Expression of Interest (EOI) to host } \\
\text { a student and Guide for Host } \\
\text { Organisations }\end{array}$ \\
\hline Support students during placement & Embed WIL in curriculum & $\begin{array}{l}\text { Support for partners while students } \\
\text { are undertaking WIL opportunities }\end{array}$ \\
\hline $\begin{array}{l}\text { Conduct debriefings to maximise } \\
\text { learning outcomes }\end{array}$ & $\begin{array}{l}\text { Deliver WIL Units - Engaging with } \\
\text { Industry; } \quad \text { Engaging with } \\
\text { Community }\end{array}$ & \\
\hline $\begin{array}{l}\text { Provide tools for students to ensure } \\
\text { due diligence, including risk } \\
\text { assessments, legal agreements, } \\
\text { travel processes and insurance }\end{array}$ & $\begin{array}{l}\text { Maintain currency of best practice } \\
\text { by involvement in peak bodies and } \\
\text { research in } T \& L \text { projects }\end{array}$ & \\
\hline
\end{tabular}

\section{Conclusion}

The Australian job market is undergoing a transformation which is having a profound impact on employment outcomes for students and which in turn demand learning experiences that will facilitate a skill set commensurate with the employee of the 21 st century. This paper has highlighted a strategic approach to building institutional capacity in adopting a work integrated learning framework to enhance not only the student experience, but also employability. An authentic and holistic student experience that embraces WIL curricula and enacts a teaching and learning philosophy that promotes student employability is of the essence. The multi- 
faceted, staged approach to driving a WIL culture across the organisation highlights the significance of a strong and cohesive project team who share common goals; the establishment of a clear and coherent institutional framework which reflects long term ambitions; the development and enactment of a comprehensive communication plan; the implementation of manifold approaches to staff and student engagement; and creating extensive internal and external collaborations to efficiently broadcast outcomes. The likelihood of accomplishing long term sustainability is heightened with considered execution of each of these phases. The project team has worked determinedly to engage the university community and embed WIL practices that provide Curtin with a point of difference in the competitive educational market.

\section{Acknowledgements}

The authors gratefully acknowledge the significant contribution made to this paper by the following members of the WIL project team: Kym Sher (Partnership Coordinator: Science and Engineering), Joshua Soh (Partnership Coordinator: Curtin Business School), Kristy Goodchild, (WIL Designer), Denise D'Cruz, (WIL Designer), and Susan Walsh, (Project Officer). 


\section{References}

Barber, M., Donnelly, K., \& Rizvi, S. (2013). An avalanche is coming: Higher education and the revolution ahead. London, England: Institute for Public Policy Research.

Bosco, A., \& Ferns, S. (2014). Embedding authentic assessment in work integrated learning assessment. Asia Pacific Journal of Cooperative Education. In Press.

Curtin University. (2014a). The WIL Guidelines. https://ctl.dev.curtin.edu.au/wil/local/docs/WIL Guidelines pdf

Curtin University. (2014b). Teaching and Learning Handbook. http://ctl.curtin.edu.au/professional development/tl handbook.cfm

DeZure, D. (Ed.). (2000). Learning from change. Stylus Publishing: Virginia, USA.

Edwards, D., Perkins, K., Pearce, J., \& Hong, J. (2015). Work integrated learning in STEM in Australian universities: Final Report. Office of the Chief Scientist. ACER.

Ernst \& Young. (2012). University of the future: A thousand year old industry on the cusp of profound change. Retrieved from http://www.ey.com/Publication/vwLUAssets/University of the future/\$FILE/Universit $\mathrm{y}$ of the future 2012.pdf

EY Megatrends (2015). Making sense of a world in motion. EYGM Ltd. http://www.ey.com/Publication/vwLUAssets/ey-megatrends-report-2015/\$FILE/eymegatrends-report-2015.pdf

Ferns, S., Campbell, M., \& Zegwaard, K. (2014a). Work integrated learning. In S. Ferns (Ed.), Work integrated learning in the curriculum HERDSA Guide. NSW: Higher Education and Development Society of Australasia Inc.

Ferns, S., Le Clus, M., Lilly, L., Cooper, L., Murphy, M., Rowbottom, D., O'Shaughnessy, A., Sher, K., \& Soh, J. (2014b). A strategic approach for building partnerships to enhance graduate employability: Driving institutional engagement. ACEN Conference. Gold Coast.

Ferns, S., \& Moore, K. (2012). Assessing student outcomes in fieldwork placements: An overview of current practice. Asia-Pacific Journal of Cooperative Education, 13(4). 207-224.

Ferns, S., Smith, C., \& Russell, L. (2014c). Complex problem complex research design: Researching the impact of WIL on employability. WACE $10^{\text {th }}$ International Symposium on Cooperative Education \& Work-integrated Learning. University West Trollhattan,Sweden. http://www.waceinc.org/uwest2014/proceedings/Australia/Sonia\%20Ferns\%20\%20Australia.pdf

Foundation for Young Australians. (2015). The new work order: Ensuring young Australians have skills and experience for the jobs of the future, not the past. Retrieved from http://www.acara.edu.au/verve/ resources/fya-future-of-work-report-final-Ir.pdf

Fullen, M., \& Scott, G. (2009). Turnaround leadership. Jossey-Bass: San Francisco, CA.

George, C., Collins, D., Gill, B., \& Cole, K. (1987). Supervision in action: The art of managing others. New Jersey, USA: Prentice-Hall.

Gladwell, M. (2001). The tipping point: How little things can make a big difference. London, UK: Abacus.

Hagel, J., Brown, J.S., Mathew, R., Wooll, M., \& Tsu, W. (2014). The lifetime learner: A journey through the future of postsecondary education. Deloitte University Press. 
Hodges, D. (2011). The assessment of student learning in cooperative and work-integrated education. International Handbook for Cooperative \& Work-integrated Education. 2nd Edition. World Association for Cooperative Education Inc., 53-62.

Kay, J., Russell, L., Winchester-Seeto, T., Rowe, A., \& Le Clus, M. (2014). External stakeholders in WIL. In S. Ferns (Ed.), Work integrated learning in the curriculum HERDSA Guide. NSW: Higher Education and Development Society of Australasia Inc.

McNamara, J. (2011). The challenge of assessing professional competence in work integrated learning. Assessment \& Evaluation in Higher Education. 38(2),183-197. doi/abs/10.1080/02602938.2011.618878

Mueller, J. (2012). Authentic assessment toolbox: What is authentic assessment? Retrieved February 18, 2013, from http://ifmueller.faculty.noctrl.edu/toolbox/whatisit.htm\#top

Senge, P. (1994). The fifth discipline fieldbook: Strategies and tools for building a learning organisation. London, UK: Nicholas Brealy Publishing.

Shavelson, R. J., Klein, S., \& Benjamin, R. (2009). The limitations of portfolios. (October 16). Retrieved February 18, 2014, from http://www.insidehighered.com/views/2009/10/16/shavelson

Smith, C., Ferns, S., \& Russell, L. (2014). Assessing the impact of work integrated learning on student work-readiness. Final Report. Sydney, NSW: Office of Learning and Teaching.

Thomas, L. (2012). Building student engagement and belonging in higher education at a time of change: A summary of findings and recommendations from what works? Student Retention \& Success programme. Commissioned by the Paul Hamlyn Foundation and the Paul Hamlyn Foundation. York, United Kingdom: Paul Hamlyn Foundation

Universities Australia. (2014a). Statement of Intent. Retrieved from http://cdn1.acen.edu.au/wp-content/uploads/2013/03/WIL-statement-of-intent.pdf

Universities Australia. (2014b). National WIL Strategy. Retrieved from http://cdn1.acen.edu.au/wp-content/uploads/2015/03/National-WIL-Strategy-inuniversity-education-032015.pdf

van Rooijen, M. (2011). Transforming 21st century engagement: From work-integrated learning (WIL) to learning-integrated work (LIW). Journal of Cooperative Education and Internships, 45(01), 5-10.

Varghese, N. (2011). Globalization and cross-border education: Challenges for the development of higher education in Commonwealth countries. UNESCO and International Institute for Education Planning.

Yorke, M. (2011). Work-engaged learning: Towards a paradigm shift in assessment. Quality in Higher Education. 17(1), 117-130. Retrieved from http://www.uq.edu.au/teach/assessment/docs/brief-21-may2011.pdf

Yorke, M., \& Knight, P. (2004). Learning, curriculum and employability in higher education. New York: Routledge Falmer. 